\title{
At-sea density and abundance estimates of the olive ridley turtle Lepidochelys olivacea in the eastern tropical Pacific
}

\author{
Tomoharu Eguchi*, Tim Gerrodette, Robert L. Pitman, Jeffrey A. Seminoff, \\ Peter H. Dutton
}

Southwest Fisheries Science Center, National Marine Fisheries Service, 8604 La Jolla Shores Drive, La Jolla, California 92037, USA

\begin{abstract}
The first at-sea estimates of density and abundance of the olive ridley turtle Lepidochelys olivacea in the eastern tropical Pacific (ETP) were produced from shipboard line-transect data. Multi-ship surveys were conducted in 1992, 1998, 1999, 2000, 2003, and 2006 in the area defined by $5^{\circ} \mathrm{N}, 120^{\circ} \mathrm{W}$, and $25^{\circ} \mathrm{N}$ and the coastline of Mexico and Central America. Sighting data of olive ridleys were stratified by survey effort and sighting conditions, thereby reducing potential biases from heterogeneous observation conditions. Dive data from satellite telemetry studies were used to correct for the proportion of turtles that were submerged and unavailable for detection during the surveys. A weighted average of the 5 by-year estimates (1998 to 2006) was 1.39 million (coefficient of variation, $\mathrm{CV}=19.7 \%$; approximate $95 \% \mathrm{CI}: 1.15$ to 1.62 million). Our findings are consistent with the dramatic increases of olive ridley nesting populations that have been reported over the past decade for beaches in the ETP.
\end{abstract}

KEY WORDS: Line transect · DISTANCE · Endangered species

Resale or republication not permitted without written consent of the publisher

\section{INTRODUCTION}

The olive ridley turtle Lepidochelys olivacea occurs in tropical and subtropical regions throughout the world's oceans and is the most abundant marine turtle (Pritchard 1997). The species exhibits solitary and 'arribada' nesting, the latter being a strategy unique to the genus Lepidochelys, during which 100s to 1000s of females nest synchronously at a nesting beach (Richard \& Hughes 1972, Cliffton et al. 1995, Pritchard 1997). During exceptionally large arribadas, such as those that occur along the Pacific coasts of Costa Rica and Mexico, and the Indian Ocean coast of northeastern India, 100000 or more olive ridleys may nest over the course of 1 to $3 \mathrm{~d}$ (Márquez et al. 2002, Shanker et al. 2003). Despite the great abundance of arribada nesters, their numbers are comparable to those of solitary nesters, due to the expansive nesting range of the species (Abreu-Grobois \& Plotkin 2007). For example, arribada nesting along the Pacific coast of the Americas occurs at only a few sites, whereas solitary nesting occurs at thousands of beaches from northwestern Mexico to Ecuador (Cliffton et al. 1995, Alava et al. 2007)

Like other marine turtles, olive ridleys have been affected by a variety of human activities such as direct harvest of eggs and turtles, nesting habitat destruction, and fishery bycatch (Cheng \& Chen 1997, Pritchard 1997, Pandav et al. 1998). In the eastern Pacific, for example, commercial exploitation of olive ridleys during the 1960s and 1970s resulted in annual harvests of 75000 to 350000 turtles in Mexico (Peñaflores et al. 2000) and tens of thousands of olive ridleys each year from Ecuadorian waters (Green \& Ortiz-Crespo 1995). More recently, olive ridleys have been subjected to incidental capture resulting from various fishing activ- 
ities (Cheng \& Chen 1997, Pandav et al. 1998, Lewison et al. 2004, Pinedo \& Polacheck 2004), which are thought to be a significant source of mortality. As a result of these impacts, nesting abundances on many of the primary nesting beaches have declined (Valverde et al. 1998, Shanker et al. 2003) to the extent that several olive ridley arribadas appear to be an endangered phenomenon (Brower \& Malcolm 1991). Due to these ongoing threats and ensuing population declines, the olive ridley was officially protected in Mexico in 1990 (DOF 1990), and remains listed as 'Endangered' in the IUCN World Conservation Union Red List (IUCN 2006) and included in Appendix I of the Convention on International Trade in Endangered Species (CITES). Despite a worldwide increase in research and conservation of olive ridleys, few data are available on their density and abundance in most regions.

Successful management of a population requires information about mortality, recruitment, and temporal changes in abundance or density. Longitudinal estimates of abundance or density are necessary for management and monitoring of marine turtle populations. For marine turtles, the annual number of females at nesting beaches has been used as an index of abundance (Meylan 1995, Troëng et al. 2004, Kaplan 2005). Because the proportion of the total females nesting in any one season may vary substantially from year to year (Broderick et al. 2001, Shanker et al. 2004, Dutton et al. 2005), inter-annual variability in nesting abundance does not necessarily reflect actual changes in abundance. In the case of olive ridleys, this problem is exacerbated by the difficulty of generating accurate abundance estimates of nesting females during arribada events.

An alternative and complementary method to nesting beach surveys is sampling at sea. Transect sampling, such as line-transect and strip-transect surveys, has been used successfully to estimate density and abundance of marine mammals and marine birds around the world (Caretta et al. 2001, Dawson et al. 2004, Castège et al. 2004, Gerrodette \& Forcada 2005, Lowry \& Forney 2005). However, only a few studies have used distance sampling methods to estimate marine turtle abundance or density at sea. Beavers \& Ramsey (1998) analyzed sighting data for the hardshelled turtles, olive ridley Lepidochelys olivacea, green turtle Chelonia mydas, hawksbill Eretmochelys imbricata, and the loggerhead Caretta caretta, in the eastern tropical Pacific (ETP) based on earlier data collected in the same area. Because their study was focused on the methodological importance of using environmental covariates, however, they pooled all hard-shelled turtle species (Cheloniidae) as one group. Species-specific density estimates, therefore, were not provided. Along the central coast of California, aerial line transect surveys have provided annual abundance estimates of leatherback turtles Dermochelys coriacea in the foraging area (Benson et al. 2006). Aerial linetransect surveys are also proving to be effective for determining spatial distribution and density of loggerhead turtles along the Pacific coast of Baja California, Mexico (Seminoff et al. 2006).

In this study, we estimated densities of olive ridleys in the ETP from ship-based line-transect sighting data for 1992, 1998, 1999, 2000, 2003, and 2006. We compared qualitatively our finding to changes in abundance reported for nesting beaches. These results can be used to evaluate future changes in the density and abundance of olive ridley turtles in the ETP and to relate total estimates of abundance to nesting beach counts.

\section{MATERIALS AND METHODS}

The study was conducted in an area that extended from $5^{\circ} \mathrm{N}$ northward to $25^{\circ} \mathrm{N}$ and from $120^{\circ} \mathrm{W}$ eastward to the coastlines of Mexico and Central America. (6 $272850 \mathrm{~km}^{2}$; Fig. 1). The Southwest Fisheries Science Center of the National Marine Fisheries Service (SWFSC), National Oceanic and Atmospheric Administration (NOAA) conducted line-transect surveys in the study area during summer/autumn of 1992, 1998, 1999, 2000, 2003, and 2006. Turtles were surveyed from 2 research vessels ( 3 vessels in 1998) that were being used to survey marine mammals. Line-transect data collection procedures are described in Kinzey et al. (2000). The eye height of observers was approximately $11 \mathrm{~m}$ above sea level. Observers were located on the port and starboard sides of the observation deck and used $25 \times 150 \mathrm{~mm}$ deck-mounted binoculars to search for animals from the track line to $90^{\circ}$ of their respective sides. The third observer searched the track line with the naked eye and with hand-held $7 \times 50 \mathrm{~mm}$ binoculars. Radial distances were measured with reticles in the binoculars, and horizontal angles from the trackline were measured to the nearest degree with a pointer attached to the binocular column. Perpendicular distance from the track line was calculated later as (radial distance) $\times$ sine (horizontal angle).

The study area was divided into 4 strata; offshore north, offshore south, coastal north, and coastal south (Fig. 1). The coastal strata, bounded by the $1000 \mathrm{~m}$ depth contour, had greater survey effort per unit area in most years. The division between north and south followed the EEZ boundary of Mexico, which was necessary because surveys could not be conducted in Mexican waters in 1992. We emphasize that the stratification was based solely on the logistical con- 

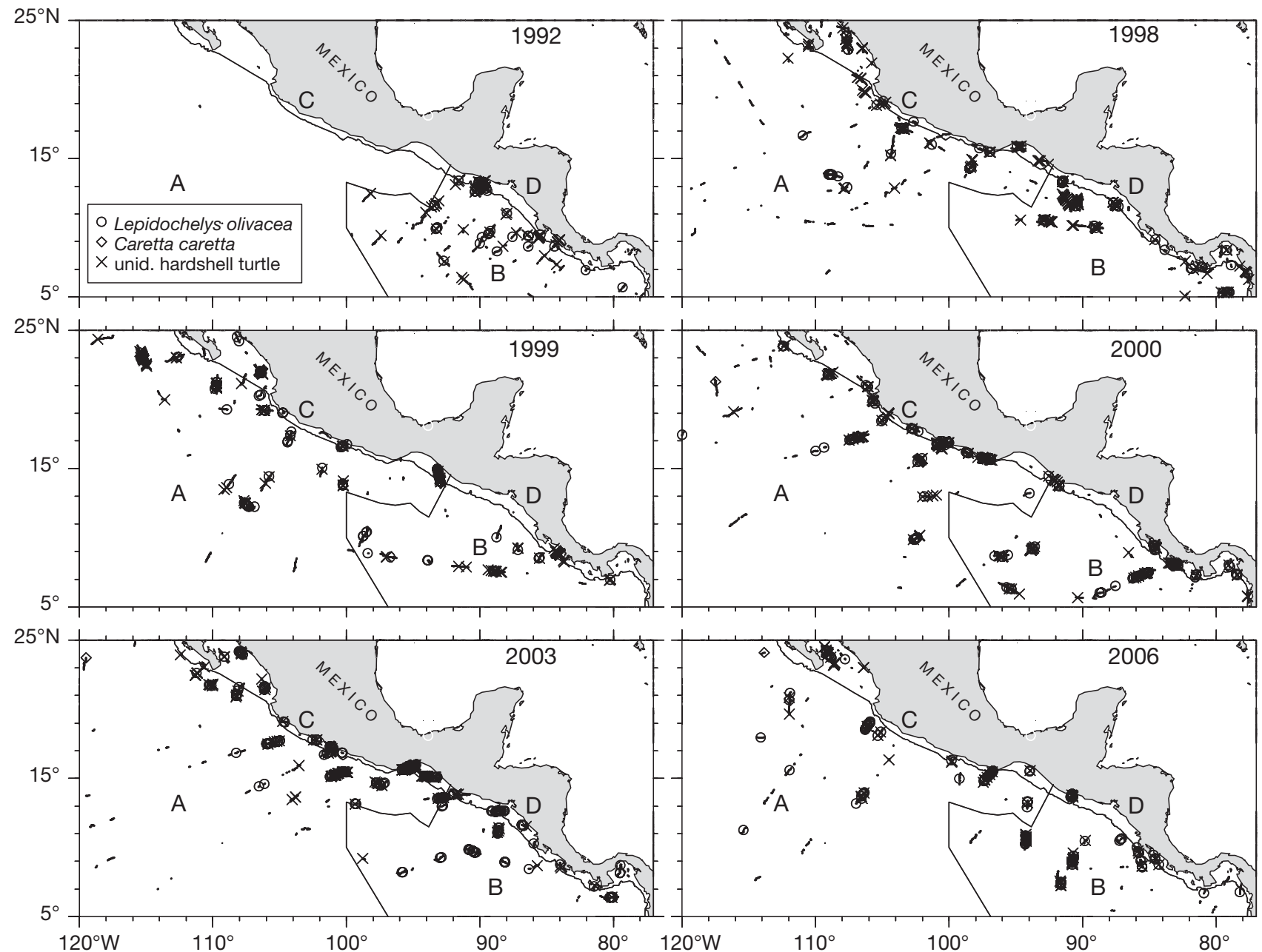

Fig. 1. Study area, turtle sightings and line-transect search effort for 6 surveys in the eastern tropical Pacific between 1992 and 2006. Thin solid lines show 4 strata; thick short lines show segments of search effort in calm sea conditions (Beaufort $\leq 2$ ). Strata: northern offshore (A), southern offshore (B), northern coastal (C), and southern coastal (D). unid: unidentified

straints of the sampling design and was not done for ecological or biological reasons.

Turtle sightings were identified as olive ridley, loggerhead, green, or leatherback turtles. Although turtle sightings were not always identified to species, for the analysis we assumed that all unidentified turtles were either olive ridleys or loggerheads, because only 1 green turtle (1998) and 1 leatherback turtle (2003) were identified in the study area over the entire course of the study. We assigned each unidentified turtle to either loggerhead or olive ridley based on the observed proportion of sightings with known species within each stratum and year

We used line-transect analysis for estimating the density of olive ridleys in the ETP. Each day was treated as a sampling unit. The theory and analytical methods are described in detail in Buckland et al. (2001, 2004). Based on the assumption of the equal detection probabilities of olive ridleys and logger- heads, we used both species and unidentified hardshell turtles for estimating detection functions $(g(y)$, where $y$ is the perpendicular detection distance). To estimate the density of olive ridleys from identified and unidentified species, we first estimated the proportion of olive ridleys among the identified species for each stratum. The estimated proportion was used to compute the number of olive ridleys for unidentified sightings. The estimated number of olive ridley sightings, then, was used to determine the density of the species $(D)$ at the ocean surface. Finally, the total density of olive ridleys, including those that are submerged during the surveys, was estimated using published and unpublished information on the proportion of the time olive ridleys spend at the ocean surface during daylight hours (see below, this section). We made an assumption that available data are representative of diving durations of olive ridleys in the study area. To reduce the variability in detection probability due to 
sea conditions, only sighting data obtained at a Beaufort sea state $<3$ were used in the analyses. Beaufort sea state, however, was used as a potential covariate which affected the sighting probability (Buckland et al. 2001, Thomas et al. 2003). Method of sighting, either unaided eye or $25 \times 150 \mathrm{~mm}$ binoculars, was also considered as a covariate.

Buckland et al. (2001) recommended that truncation of 5 to $10 \%$ of the largest perpendicular distances or the truncation distance, $w$, be chosen such that the detection probability function at $w$ was approximately 0.15 , i.e. $g(w) \cong 0,15$. We truncated all sightings at a perpendicular distance of $1.5 \mathrm{~km}$ from the track line, which eliminated approximately $14 \%$ of all data (261 out of 1833). In an analysis of line-transect data, one has to find the best analytical model that describes the detection probability of objects as a function of distance; this is known as the detection function. We used half-normal and hazard-rate functions with cosine adjustment terms as possible models for probability density functions of perpendicular distances. To determine the fit of each model to data, chi-square goodness-of-fit tests and visual inspections of observed and expected detection probabilities were conducted. Among reasonable candidate models, Akaike's Information Criterion, corrected for small samples sizes ( $\mathrm{AICc}_{\text {; }}$ Sugiura 1978) was used to select the most parsimonious model for our data.

Sightings without perpendicular distances occurred in areas of very high turtle density, when observers could not record angle and distance to each turtle as the ship moved along the trackline. Under these conditions, observers kept a simple tally of the number of turtles seen. Sightings without perpendicular distances were not used for estimating the detection function $(g(y))$, but were used for estimating turtle density, under the assumption that the same detection function applied. Consequently, our analysis consisted of 2 stages. First, we determined the most appropriate detection function for each year's data using perpendicular distances, including unidentified turtles. We assumed that the sighting function was equal among geographic strata, adjusted for sea state and sighting method. Second, estimated parameters for the detection function and all sightings (with or without perpendicular distances) were used to estimate the density of olive ridleys for each stratum. In the latter step, each unidentified sighting was randomly assigned as either a loggerhead or an olive ridley according to the proportion of observed turtles identified as olive ridleys in the dataset (Table 1).

We used a randomization method to compute uncertainty around estimated densities. Using each day as a sampling unit within each year, data were randomly selected with replacement to form 4999 randomized datasets of the same size (i.e. the number of sampling days). For each randomized dataset, estimated parameters from the best model were used to compute the density of turtles. These 5000 density estimates (using 4999 randomized datasets and 1 true dataset) were used to find a confidence interval around the estimated density from the true dataset.

Table 1. Number of turtles identified during the ETP surveys at a Beaufort sea state of <3. CC: loggerheads Caretta caretta; LO: olive ridleys Lepidochelys olivacea; UT: unidentified turtles. Parentheses: number of turtles sighted without perpendicular distances. Strata: (A) northern offshore, (B) southern offshore, (C) northern coastal, (D) southern coastal. (-) no data

\begin{tabular}{|c|c|c|c|c|c|c|c|}
\hline Species & Stratum & 1992 & 1998 & 1999 & 2000 & 2003 & 2006 \\
\hline \multirow[t]{4}{*}{$\mathrm{CC}$} & A & - & 0 & 21 & 1 & 1 & 2 \\
\hline & B & 0 & 0 & 0 & 0 & 0 & 0 \\
\hline & $\mathrm{C}$ & - & 0 & 0 & 1 & 0 & 0 \\
\hline & $\mathrm{D}$ & 0 & 0 & 0 & 0 & 0 & 0 \\
\hline \multirow[t]{4}{*}{ LO } & A & - & 23 & 45 & 69 (30) & $101(1)$ & $124(36)$ \\
\hline & B & 20 & $28(5)$ & 20 & 36 & 229 (158) & $103(50)$ \\
\hline & $\mathrm{C}$ & - & 5 & 365 (46) & 49 (19) & $100(28)$ & 69 (31) \\
\hline & $\mathrm{D}$ & 36 & $14(6)$ & 0 & 24 & $161(85)$ & $22(8)$ \\
\hline \multirow[t]{4}{*}{ UT } & A & - & 39 & 65 & 148 & $72(22)$ & $25(3)$ \\
\hline & B & $33(2)$ & $120(14)$ & 15 & 31 & $13(8)$ & $47(5)$ \\
\hline & $\mathrm{C}$ & - & $533(471)$ & 32 & $101(53)$ & $413(374)$ & 52 \\
\hline & D & 101 & $23(6)$ & 185 (123) & 52 & 122 (109) & 4 \\
\hline \multirow[t]{5}{*}{ Total } & A & - & 62 & 131 & 218 & 174 & 151 \\
\hline & B & 53 & 148 & 35 & 67 & 242 & 150 \\
\hline & $\mathrm{C}$ & - & 538 & 397 & 151 & 513 & 121 \\
\hline & $\mathrm{D}$ & 137 & 37 & 185 & 76 & 283 & 26 \\
\hline & All & 190 & 785 & 748 & 512 & 1212 & 448 \\
\hline
\end{tabular}


We used DISTANCE (v. 4.1, Release 2; Thomas et al. 2003) to find the best detection function for each year and estimate the parameters of detection functions (first stage). Estimation of densities and their confidence intervals (second stage) were accomplished by creating routines in Matlab (Mathworks). Matlab routines are available from T.E. upon request. We report 2.5 and 97.5 percentiles of 5000 density estimates as the measure of uncertainty unless otherwise noted.

Because submerged marine turtles are not observable at the sea surface, estimated density refers to the olive ridleys at the ocean surface during the time of survey. Consequently, in order to estimate the total abundance of olive ridleys in the area, we need to account for the proportion of time turtles spend at or near the ocean surface. Parker et al. (2002) reported that olive ridleys in our study area spent 22 to $56 \%$ (mean $=37 \%, \mathrm{n}=8$ ) of their time at near the ocean surface $(<1 \mathrm{~m})$ between 09:00 and 14:00 h. In another study within our study area, olive ridleys that were caught in long-line fishery operations and released with satellite transmitters spent an average of $46 \%$ (range $=29.5$ to $75.8 \%, \mathrm{n}=9$ ) above $5.4 \mathrm{~m}$ between 09:00 and 14:00 h (L. McNaughton, Joint Institute for Marine Research and Atmospheric Research, University of Hawaii, pers. comm.). Polovina et al. (2004) reported that olive ridleys spent approximately $20 \%$ of their time at the surface $(n=2)$, although the study was conducted west of our study area. These studies showed that a fraction of turtles were at the surface during the time of survey, indicating that diving behavior has a negative bias on the density estimation from line-transect analysis. Although the small sample sizes of these studies make the generalization of dive patterns of olive ridleys difficult, we use $40 \%$ as the best estimate of the proportion of the total time olive ridleys spend their time at the ocean surface. Because the study by Polovina et al. (2004) was outside of our study area, we relied more on the mean values from studies by Parker et al. (2002) and McNaughton. We rounded the average of the 2 mean values from these 2 studies to obtain $40 \%$.

To compute the total abundance for each year $\left(N_{t}\right)$, the estimated density for each stratum was weighted by the proportional area (p 89 of Buckland et al. 2001):

$$
\hat{N}_{t}=\frac{\sum_{i=1}^{4} A_{i} \hat{D}_{i, t}}{S}
$$

where $\hat{N}_{t}$ is the estimated $N_{t}, A_{i}$ is the area of the $i$ th stratum, $\hat{D}_{i, t}$ is the estimated density of the ith stratum for year $t$, and $s$ is the proportion of time olive ridleys spent at the ocean surface (0.4). The upper and lower confidence limits were computed in a similar manner, using the limits for each stratum. To compute the vari- ance of the abundance estimate for each year, we assumed independence of densities among strata:

$$
\operatorname{var}\left(\hat{N}_{t}\right)=\sum_{i=1}^{k_{t}}\left(\frac{A_{i}}{s}\right)^{2} \operatorname{var}\left(\hat{D}_{i, t}\right)
$$

where $k_{t}$ is the number of strata for year $t$ and $k_{t}=2$ for 1992 and $k_{t}=4$ for other years, and variance of $\hat{D}_{i, t}$ was computed using the $5000 \hat{D}_{i, t}$ values from the randomization method. Finally, to compute the overall abundance estimate between 1998 and 2006, we used the weighted average of $\hat{N}_{t}$ using the method described in Seber (1982):

$$
\bar{N}=\frac{\sum_{t=1}^{5} w_{t} \hat{N}_{t}}{\sum_{t=1}^{5} w_{t}}
$$

where $w_{t}=1 / \sigma_{t}^{2}$ and $\sigma_{t}^{2}=\operatorname{var}(\hat{N})_{t}$. The variance of this estimator is:

$$
\operatorname{var}(\bar{N})=\frac{\sum_{t=1}^{5} w_{t}\left(\hat{N}_{t}-\bar{N}\right)^{2}}{4 \sum_{t=1}^{5} w_{t}}
$$

An approximate $95 \%$ CI for $\bar{N}$ was computed using the normal approximation:

$$
\bar{N} \pm 1.960 s / \sqrt{5}
$$

where $s=\sqrt{\operatorname{var}(\bar{N})}$.

\section{RESULTS}

An average of $2700 \mathrm{~km}(\mathrm{SD}=840)$ was surveyed per annum while Beaufort sea state was $<3$ (Table 2). The total number of transect lines was $\geq 50$ per annual survey. The sample size was greatest for 1998, when surveys were conducted over a total of 90 transect lines, which covered $3731 \mathrm{~km}$ of track lines.

The number of observed turtles ranged from 448 during 2006 to 1212 during 2003 (Table 1). Among turtles that were identified to species in the field, $<5 \%$ were loggerheads. The proportion of olive ridleys varied among regions and years (Table 1). For the southern strata (offshore and coastal), olive ridleys were the only identified species, whereas loggerheads were also found in the northern strata (Table 1). The proportion of loggerheads within a stratum also varied among years. As many as ca. $65 \%$ of sightings per annum were without perpendicular distances (Table 1).

The encounter rate (turtles per $\mathrm{km}$ surveyed) ranged from 0.03 in the northern offshore stratum during the 1998 survey to 2.3 in the southern coastal stratum during the 1999 survey (Table 3). Although encounter rate was variable among strata and years, 
Table 2. Annual survey effort $(\mathrm{km})$ and number of transect lines $(\mathrm{n})$ in Beaufort sea state <3. Strata: (A) northern offshore, (B) southern offshore, (C) northern coastal, (D) southern coastal. No surveys were conducted in strata A and C in 1992

\begin{tabular}{|c|c|c|c|c|c|c|c|c|c|c|c|c|c|c|}
\hline Stratum & $\begin{array}{c}\text { Area } \\
\left(10^{6} \mathrm{~km}^{2}\right)\end{array}$ & $\begin{array}{c}8 \text { Aug- } \\
1 \text { Nov } \\
1992\end{array}$ & $\mathrm{n}$ & $\begin{array}{c}30 \text { July- } \\
4 \text { Dec } \\
1998\end{array}$ & $\mathrm{n}$ & $\begin{array}{c}1 \text { Aug- } \\
5 \text { Dec } \\
1999\end{array}$ & $\mathrm{n}$ & $\begin{array}{c}3 \text { Aug- } \\
5 \text { Dec } \\
2000\end{array}$ & $\mathrm{n}$ & $\begin{array}{c}7 \text { Aug- } \\
6 \text { Dec } \\
2003\end{array}$ & $\mathrm{n}$ & $\begin{array}{c}4 \text { Aug- } \\
1 \text { Dec } \\
2006\end{array}$ & $\mathrm{n}$ & Mean \pm SD \\
\hline A & 4.4 & - & - & 1866.7 & 43 & 1704.6 & 24 & 1510.6 & 29 & 1421 & 28 & 893.8 & 21 & $1479.3 \pm 370.1$ \\
\hline B & 1.47 & 1437 & 45 & 656.7 & 15 & 616.8 & 13 & 856.9 & 16 & 399.6 & 12 & 556.7 & 17 & $753.9 \pm 366$ \\
\hline C & 0.25 & - & - & 781.9 & 18 & 417.4 & 12 & 555.6 & 13 & 658 & 14 & 145.6 & 5 & $511.7 \pm 244.6$ \\
\hline $\mathrm{D}$ & 0.15 & 258.6 & 10 & 428.8 & 14 & 80.3 & 3 & 439.3 & 8 & 404.1 & 8 & 119.8 & 7 & $288.5 \pm 160.3$ \\
\hline Total & 6.3 & 1695.6 & 55 & 3731.4 & 90 & 2819.1 & 52 & 3362.4 & 66 & 2882.7 & 62 & 1715.9 & 50 & $2701.7 \pm 840.6$ \\
\hline
\end{tabular}

Table 3. Number of turtles (unidentified, loggerheads and olive ridleys) sighted per $\mathrm{km}$ of survey during line transect surveys in ETP. Strata: (A) northern offshore, (B) southern offshore, (C) northern coastal, (D) southern coastal. Total survey distances provided in Table 1 . No surveys were conducted in strata A and C in 1992

\begin{tabular}{|lcccccc|}
\hline Stratum & 1992 & 1998 & 1999 & 2000 & 2003 & 2006 \\
\hline A & - & 0.03 & 0.08 & 0.14 & 0.12 & 0.17 \\
B & 0.04 & 0.23 & 0.06 & 0.08 & 0.61 & 0.27 \\
C & - & 0.69 & 0.95 & 0.27 & 0.78 & 0.83 \\
D & 0.53 & 0.09 & 2.3 & 0.17 & 0.7 & 0.22 \\
All & 0.11 & 0.21 & 0.27 & 0.15 & 0.42 & 0.26 \\
\hline
\end{tabular}

the northern coastal stratum consistently had a higher encounter rate, whereas it was most variable in the southern coastal stratum. The number of sightings per day was variable: for the majority of days, sightings numbered $<10$, while the maximum number of sightings in 1 day was 469 .

The expected detection probability at $1.5 \mathrm{~km}$ ranged from ca. 0.05 to 0.25 (data not shown). In each year, there were more sightings recorded very near the track-line than could reasonably be expected. The most likely cause was rounding of distance measurements by observers in the field ('heaping'), because attraction to the moving vessel was not a reasonable explanation for turtles. To address this problem, we used binning, which masked heaping by grouping distance data (Fig. 2). After examining various binning options, we used 2 binning methods; 8 bins of an equal width and 8 bins of unequal widths. For the unequal bin widths, the width of the first bin was $0.1 \mathrm{~km}$, whereas the width of the other bins was $0.2 \mathrm{~km}$. Consequently, analyses on each year's data were conducted on 3 sets of data; 2 binned and un-binned datasets.

For the analysis of unequally binned data for 2006, we detected heaping for the second bin (187.5 to $375 \mathrm{~m})$. The model fitting algorithm apparently overfitted the most parsimonious model $[\mathrm{HR}+\cos (3)+(\mathrm{Bft}$, $\mathrm{Mt}$ )] to data (HR: hazard-rate detection function; Bft: Beaufort sea state; Mt: method of sighting). We there- fore used the second and third parsimonious models as the 2 best models. The difference in AICc values between the 2 best models $(\triangle \mathrm{AIC})$ was $<2$ for the majority of analyses, indicating both models fit equally to each dataset (Table 4). The same result was found for estimated effective strip width (ESW), where no significant difference was found between the 2 best models for all datasets (Table 4). Hereafter, we will discuss only the best model for each dataset.

The half-normal function was selected as the best key detection function for the majority of datasets (Table 4). For 2000, however, the hazard-rate key function was selected as the more appropriate model for the 3 data types (Table 4). The observation method was the only influential covariate for the detection function, except for the equally binned data for 1992, in which Beaufort sea state was the influential covariate, and for 2006, in which observation methods and sea state were both included in the best models.

Estimated ESWs among 3 datasets were significantly different for 1998, where 95\% CI did not overlap between 2 binning sets (Table 4 ). For other years, they were not different among the 3 data types. Among years, estimated ESW were greater for 1999 (0.7 km) than for other years $(0.4$ to $0.5 \mathrm{~km})$.

Regardless of model selection or binning options, density estimates were similar within each year. Point estimates of density for the entire study area were approximately 0.10 to 0.15 turtles $\mathrm{km}^{-2}$ for 1992 through 2000, but for 2003 increased to approximately 0.40 turtles $\mathrm{km}^{-2}$ (Fig. 3). The estimated density in the area, however, decreased to approximately 0.20 turtles $\mathrm{km}^{-2}$ for 2006. Changes in estimated densities were more apparent when estimates were compared among years for each stratum. Because of the large uncertainty, estimated densities were not statistically different among years (Fig. 3).

A consistent increase in density was found for the northern offshore stratum (Fig. 3), where the estimated density increased from 0.02 turtles $\mathrm{km}^{-2}(95 \% \mathrm{CI}=$ $0.01-0.04)$ in 1998 to 0.16 turtles $\mathrm{km}^{-2}(95 \% \mathrm{CI}=$ 0.05-0.33) in 2006. For other strata, however, no appar- 


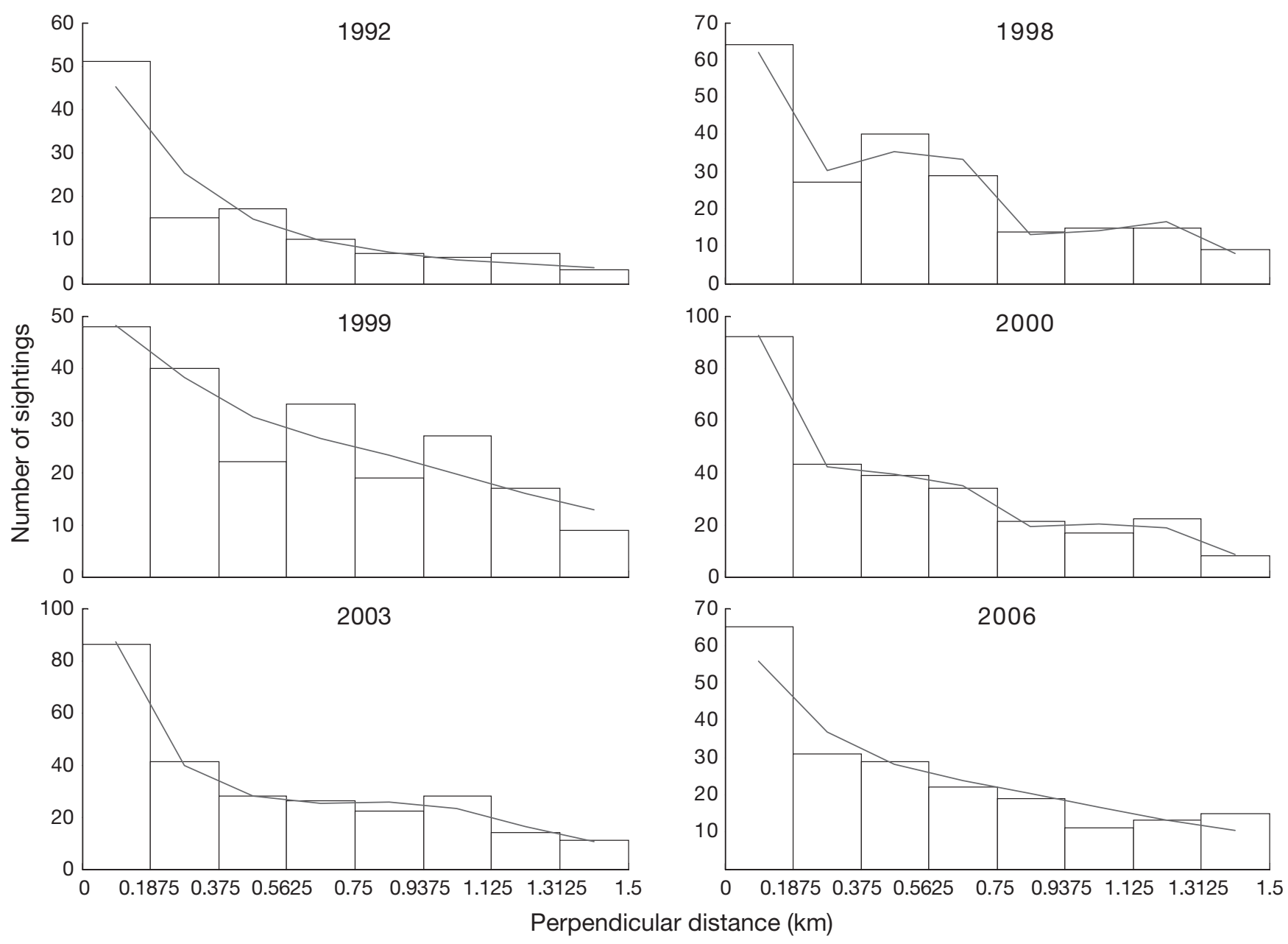

Fig. 2. Lepidochelys olivacea. Observed (bars) and expected (lines) number of sightings of olive ridleys in the ETP from research vessels. To compute the expected numbers, we used the most parsimonious model for the equal-width binning option (see 'Results' for details). Data were truncated at $1.5 \mathrm{~km}$ from the track line

ent directional change in density was found over time (Fig. 3). A large temporal variability was observed for the southern offshore stratum, where a greater density was found for 2003 than for other years. For the northern coastal stratum, the estimated densities were constant from 1998 to 2006. For the southern coastal stratum, estimated densities fluctuated from year to year, from $<0.1$ turtles $\mathrm{km}^{-2}(0.07 ; 95 \% \mathrm{CI}=0.01$ to 0.19$)$ in 1998 to more than 1.0 turtle $\mathrm{km}^{-2}(1.08 ; 95 \% \mathrm{CI}=0.00$ to 1.28 ) in 1999. The wide CIs for 1999, the lower bounds of which were zero, were the results of small sample size (3) with 1 transect line having no turtle sightings.

We estimated the total abundance (taking into account the proportion of unobservable submerged turtles) of olive ridleys in the study area to be approximately 1.1 million (95\% CI: 330000 to 2.2 million) during 1998 and 2.9 million (95\% CI: 840000 to 5.8 million) during 2006 (Table 5). The abundance estimate was greatest for 2003, where the point estimate was approximately 4.8 million and its $95 \%$ CI ranged from 0.9 million to 10.7 million (Table 5). Using the estimates for 1998 through 2006, the average abundance, weighted by the inverse of variance of 5000 abundance estimates for each year, was 1.39 million (CV $=19.7 \%$; approximate $95 \% \mathrm{CI}$ : 1.15 to 1.62 million). These abundance estimates refer to the portion of the population comprised of large juveniles and adults $(>\sim 25 \mathrm{~cm})$ that were observable during these surveys through binoculars.

\section{DISCUSSION}

\section{Line-transect analysis}

Our study provides the first estimate of at-sea density and abundance of olive ridleys in the ETP. Because these estimates are based on line-transect 
Table 4. Estimated effective strip width, ESW ( $\mathrm{km}_{;} 95 \% \mathrm{CI}$ in parentheses) for each year, and the difference in AICc values $(\triangle \mathrm{AIC})$ between the 2 best models. Models expressed as follows - detection function + adjustment function (the number of adjustment terms $)+$ \{covariates; cos: cosine adjustment function; Bft: Beaufort sea state; Mt: method of sighting. HN: half-normal detection function; HR: hazard-rate detection function. For 2006 unequal-width data, the most parsimonious model [HR + cos(3) + (Bft, Mt)] obviously overfitted to data, which indicated apparent heaping at the second bin. We, therefore, used the second and third models as our best models

\begin{tabular}{|ccccccc}
\hline \multirow{2}{*}{ Year } & Binning option & Model 1 & ESW & Model 2 & ESW & $\Delta$ AIC \\
\hline \multirow{2}{*}{1992} & Equal-width & $\mathrm{HR}+(\mathrm{Bft})$ & $0.43(0.32,0.59)$ & $\mathrm{HN}+\cos (1)+(\mathrm{Bft})$ & $0.43(0.31,0.59)$ & 2 \\
& Unequal-width & $\mathrm{HN}+\cos (1)+(\mathrm{Mt})$ & $0.43(0.35,0.54)$ & $\mathrm{HN}+\cos (2)+(\mathrm{Mt})$ & $0.41(0.33,0.51)$ & 1.06 \\
\multirow{2}{*}{1998} & No bins & $\mathrm{HN}+\cos (4)+(\mathrm{Mt})$ & $0.35(0.28,0.44)$ & $\mathrm{HN}+\cos (2)+(\mathrm{Mt})$ & $0.40(0.31,0.50)$ & 0.32 \\
& Equal-width & $\mathrm{HN}+\cos (4)+(\mathrm{Mt})$ & $0.54(0.48,0.61)$ & $\mathrm{HN}+\cos (4)+(\mathrm{Bft}, \mathrm{Mt})$ & $0.54(0.48,0.61)$ & 1.55 \\
& Unequal-width & $\mathrm{HN}+\cos (1)+(\mathrm{Mt})$ & $0.71(0.63,0.79)$ & $\mathrm{HN}+\cos (1)+(\mathrm{Bft}, \mathrm{Mt})$ & $0.71(0.63,0.79)$ & 1.57 \\
& No bins & $\mathrm{HN}+\cos (4)+(\mathrm{Mt})$ & $0.58(0.52,0.65)$ & $\mathrm{HN}+\cos (4)+(\mathrm{Bft}, \mathrm{Mt})$ & $0.58(0.52,0.65)$ & 1.85 \\
1999 & Equal-width & $\mathrm{HN}+(\mathrm{Mt})$ & $0.79(0.69,0.91)$ & $\mathrm{HN}+(\mathrm{Bft}, \mathrm{Mt})$ & $0.79(0.68,0.91)$ & 1.57 \\
& Unequal-width & $\mathrm{HN}+\cos (1)+(\mathrm{Mt})$ & $0.75(0.64,0.87)$ & $\mathrm{HN}+(\mathrm{Bft}, \mathrm{Mt})$ & $0.74(0.64,0.87)$ & 0.61 \\
\multirow{2}{*}{2000} & No bins & $\mathrm{HN}+\cos (2)+(\mathrm{Mt})$ & $0.73(0.63,0.84)$ & $\mathrm{HN}+(\mathrm{Bft}, \mathrm{Mt})$ & $0.77(0.66,0.90)$ & 0.35 \\
& Equal-width & $\mathrm{HR}+\cos (4)+(\mathrm{Mt})$ & $0.46(0.40,0.53)$ & $\mathrm{HR}+\cos (4)+(\mathrm{Bft}, \mathrm{Mt})$ & $0.46(0.40,0.52)$ & 1.91 \\
& Unequal-width & $\mathrm{HR}+\cos (4)+(\mathrm{Mt})$ & $0.47(0.41,0.55)$ & $\mathrm{HR}+\cos (4)+(\mathrm{Bft}, \mathrm{Mt})$ & $0.47(0.40,0.54)$ & 1.78 \\
2003 & No bins & $\mathrm{HR}+\cos (4)+(\mathrm{Mt})$ & $0.41(0.35,0.48)$ & $\mathrm{HR}+\cos (4)+(\mathrm{Bft}, \mathrm{Mt})$ & $0.42(0.35,0.49)$ & 1.85 \\
& Equal-width & $\mathrm{HN}+\cos (2)+(\mathrm{Mt})$ & $0.42(0.35,0.50)$ & $\mathrm{HN}+(\mathrm{Mt})$ & $0.46(0.38,0.55)$ & 0.39 \\
& Unequal-width & $\mathrm{HN}+\cos (3)+(\mathrm{Mt})$ & $0.34(0.29,0.41)$ & $\mathrm{HN}+\cos (3)+(\mathrm{Bft}, \mathrm{Mt})$ & $0.33(0.28,0.40)$ & 1.05 \\
2006 & No bins & $\mathrm{HN}+\cos (3)+(\mathrm{Mt})$ & $0.36(0.30,0.44)$ & $\mathrm{HR}+\cos (3)+(\mathrm{Mt})$ & $0.31(0.26,0.38)$ & 0.23 \\
& Equal-width & $\mathrm{HN}+(\mathrm{Bft}, \mathrm{Mt})$ & $0.61(0.52,0.73)$ & $\mathrm{HN}+\cos (3)+(\mathrm{Bft}, \mathrm{Mt})$ & $0.53(0.45,0.62)$ & 0.15 \\
& Unequal-width & $\mathrm{HN}+(\mathrm{Bft}, \mathrm{Mt})$ & $0.60(0.51,0.71)$ & $\mathrm{HN}+\cos (1)+(\mathrm{Mt})$ & $0.55(0.47,0.65)$ & 0.38 \\
& No bins & $\mathrm{HR}+\cos (1)+(\mathrm{Mt})$ & $0.34(0.27,0.43)$ & $\mathrm{HR}+\cos (2)+(\mathrm{Mt})$ & $0.41(0.33,0.51)$ & 3.11 \\
\hline
\end{tabular}

analyses, the underlying assumptions for line-transect analyses must be examined. The primary assumptions for line-transect analyses are: (1) turtle movements are independent of the observers (i.e. ships did not affect turtle movements), (2) sighting distance measurements are exact, and (3) all turtles on the track line are detected. We think the ships had negligible effects on behavior and movements of olive ridleys during the survey.

Sighting distances measured using binocular reticles are variable but accurate on average (Kinzey \& Gerrodette 2003). However, observers may round the distance to convenient values (i.e. heaping; Buckland et al. 2001). We found evidence of heaping in our distance data. To address possible biases in estimated density due to heaping, we explored 2 binning options (see 'Results'). Estimated densities of olive ridleys, however, were unaffected by data manipulations, with the exception of 2006 data. Although statistically insignificant, point estimates among 3 data types for 2006 data were more variable than for other years $(2$ northern strata; Fig. 4). This was a result of the difference in estimated ESW among binning options (Table 4).

Finally, turtles were detected at long distances $(>5 \mathrm{~km})$ from the ship, indicating that all turtles on the track line were probably detected if they were at the surface. A sighting of a turtle, however, is conditional on the turtle being at the water surface at the time of survey. Because olive ridleys can stay sub- merged for as long as 180 to $240 \mathrm{~min}$ in the ETP and in the Arafura Sea (Parker et al. 2002, McMahon et al. 2007), a large proportion of olive ridleys may have been submerged, therefore, unavailable for sighting during the survey.

\section{Density and abundance estimates}

Although not statistically different-due to the large uncertainty around point estimates - the point estimate of density was greater for 2003 than for the other years (Fig. 4). There are several possible explanations for the change in the estimated density. The change may be caused by bias from survey designs and analyses, biological reasons, stochasticity that was not incorporated into our modeling, or a combination of these factors. For our sampling design, track lines were placed in the study area so that every location had an equal chance of being sampled. In our analyses, 2 best models provided comparable estimates for the 3 data types for all years. Consequently, we think the observed variability in the estimated density was not an artifact of analysis or survey design.

Olive ridleys may change their behavior over time, and may, for example, aggregate at a certain time of the year, perhaps responding to environmental cues (Plotkin et al. 1995). Polovina et al. (2004) reported that olive ridleys in the tropical Pacific are associated with 

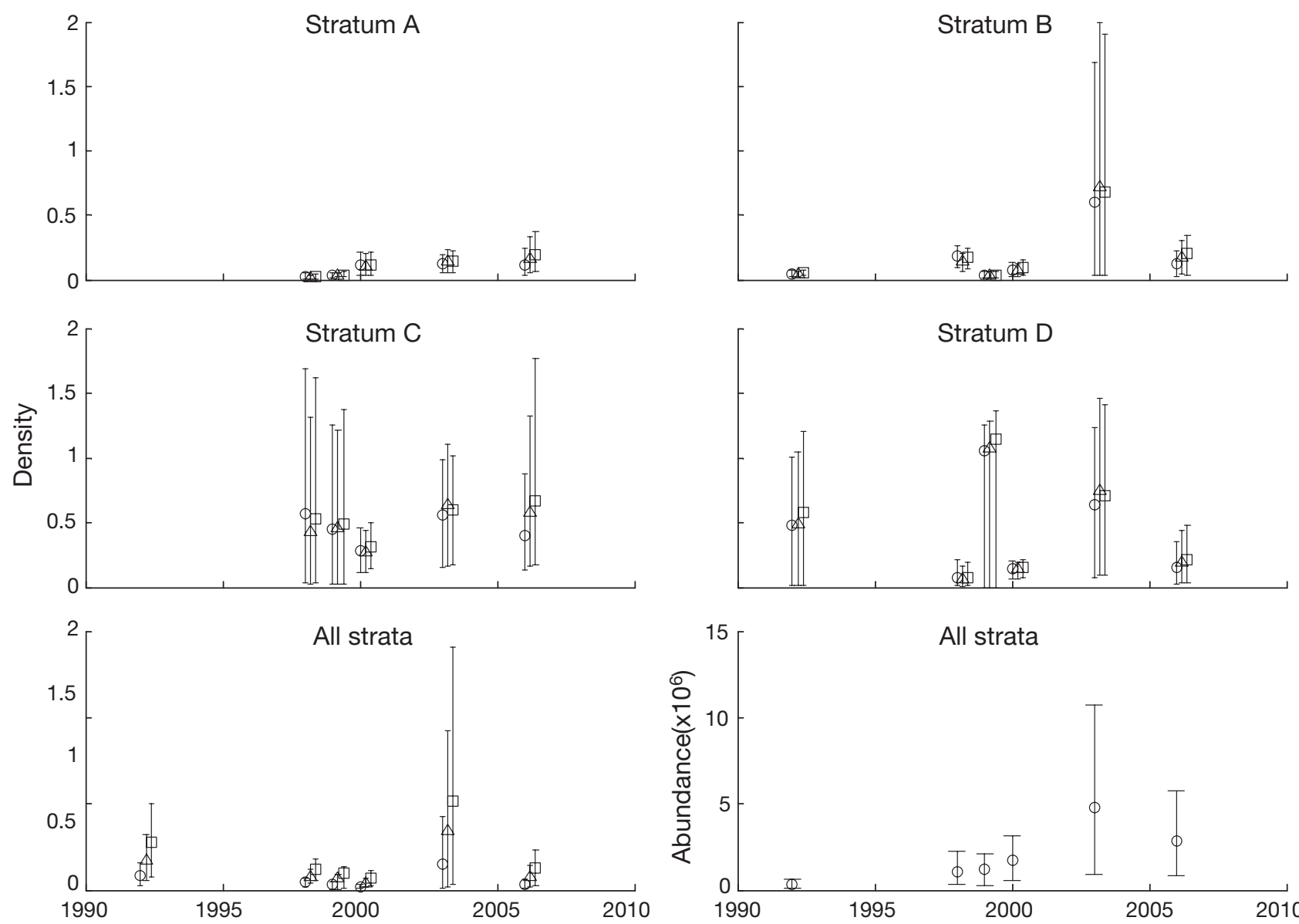

All strata

Fig. 3. Lepidochelys olivacea. The estimated density (turtles $\mathrm{km}^{-2}$ ), total abundance, and $95 \%$ CI around the estimates for olive ridleys in the ETP. For each year, estimates for 3 binning options $( \pm$ SE) are shown; from left to right, equal-width binning (O), unequal-width binning $(\Delta)$, and no binning $(\square)$. See 'Results' for details of these binning options. To compute the total abundance, the median among the 3 data types was used. Strata are northern offshore (A), southern offshore (B), northern coastal (C), and southern coastal (D)

Table 5. Lepidochelys olivacea. Estimated abundances (in millions) of olive ridleys in the 4 strata in the ETP between 1992 and 2006. For each combination of year and stratum, the estimate [95\% CI] are computed using the estimated parameters for the most parsimonious model (Table 4). To compute the estimated abundance for each year, the estimated density for each stratum was multiplied by the corresponding area and divided by the proportion of time olive ridleys spent at the ocean surface (0.4). Strata are northern offshore(A), southern offshore (B), northern coastal (C), and southern coastal (D)

\begin{tabular}{|c|c|c|c|c|c|c|}
\hline \multirow[t]{2}{*}{ Stratum } & \multicolumn{6}{|c|}{ Year } \\
\hline & 1992 & 1998 & 1999 & 2000 & 2003 & 2006 \\
\hline A & - & $0.22(0.06,0.41)^{\mathrm{b}}$ & $0.43(0.22,0.65)^{\mathrm{b}}$ & $1.20(0.34,2.28)^{\mathrm{b}}$ & $1.63(0.66,2.57)^{b}$ & $1.81(0.58,3.66)^{b}$ \\
\hline B & $0.18(0.11,0.26)^{a}$ & $0.51(0.25,0.75)^{\mathrm{b}}$ & $0.11(0.05,0.22)^{\mathrm{a}}$ & $0.29(0.10,0.48)^{a}$ & $2.50(0.13,7.00)^{\mathrm{C}}$ & $0.65(0.15,1.12)^{b}$ \\
\hline $\mathrm{C}$ & - & $0.33(0.02,1.01)^{\mathrm{c}}$ & $0.29(0.02,0.75)^{b}$ & $0.17(0.07,0.29)^{a}$ & $0.37(0.11,0.63)^{\mathrm{C}}$ & $0.36(0.10,0.82)^{b}$ \\
\hline $\mathrm{D}$ & $0.19(0.00,0.40)^{b}$ & $0.03(0.005,0.08)^{\mathrm{c}}$ & $0.42(0.00,0.49)^{b}$ & $0.06(0.03,0.08)^{\mathrm{c}}$ & $0.27(0.04,0.54)^{\mathrm{c}}$ & $0.08(0.01,0.17)^{\mathrm{b}}$ \\
\hline Total & $0.37(0.11,0.67)$ & $1.08(0.33,2.24)$ & $1.24(0.29,2.12)$ & $1.72(0.54,3.13)$ & $4.77(0.93,10.74)$ & $2.90(0.84,5.78)$ \\
\hline
\end{tabular}

the center of the Subtropical Gyre, where the water is vertically stratified with a deep thermocline. They also speculated that olive ridleys use geostrophic currents and wind-induced upwelling to reduce the energy expenditure of foraging. Generally, olive ridleys were found in the waters where sea surface temperature was approximately $27^{\circ} \mathrm{C}$ (Polovina et al. 2004, Swimmer et al. 2006). These observations indicate that distribution of olive ridleys in the Pacific Ocean is patchy and probably dynamic, corresponding to large scale 


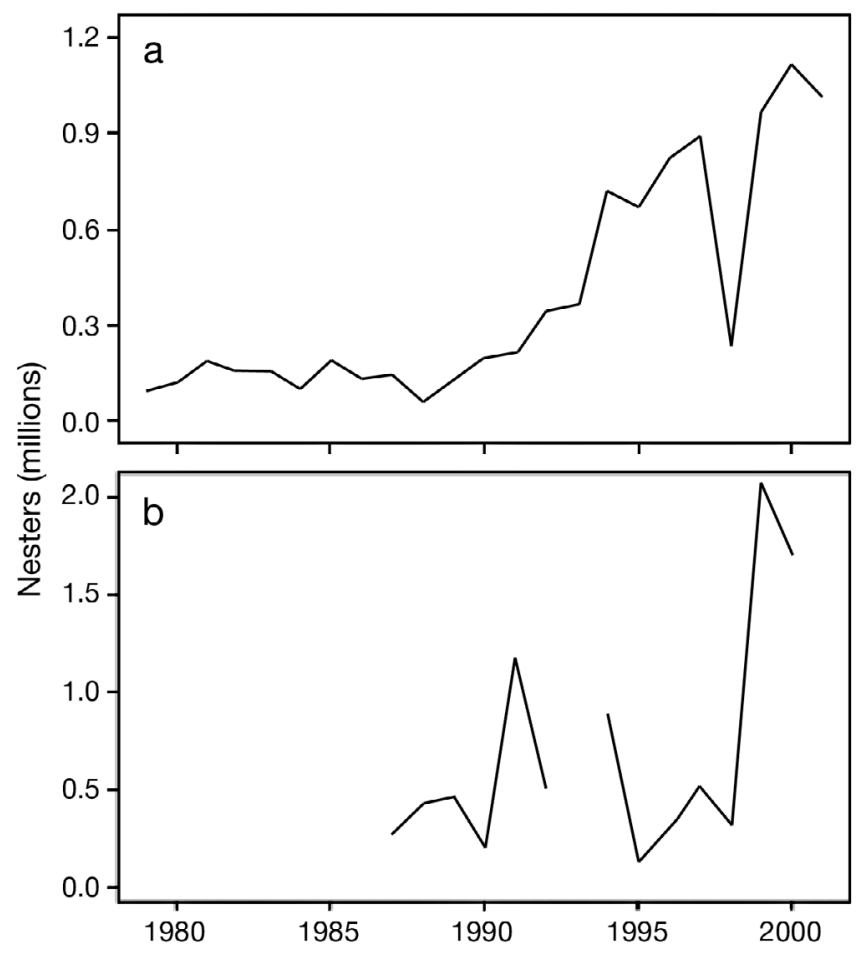

Fig. 4. Lepidochelys olivacea. Change in estimated nesting abundance of 2 major olive ridley nesting populations from the eastern Pacific (a) Playa Escobilla, Mexico (Márquez et al. 2002) and (b) Ostional, Costa Rica (Chaves 1998, 1999, 2002, Chaloupka et al. 2004)

spatial and temporal changes in ocean temperature. The greater density during 2003 in the study area may have been the result of turtles moving into the study area from elsewhere. Conversely, the lower density estimate for 2006 may have been the result of olive ridleys moving away from our study area that year.

The wide CIs for some estimates in our analyses were the result of several sources of stochasticity in our data. Extreme patchiness of olive ridleys in the study area resulted in some track lines with no observations of turtles, whereas large numbers of turtles were detected in other track lines (Fig. 2). Consequently, the randomization method resulted in wide CIs. CIs for the total abundance become much wider if the uncertainty in the proportion of time at the surface is included in the computation. Further, the variability in behavior of olive ridleys in the study area, e.g. juveniles vs. adults, mating pairs vs. single animals, spatial and temporal changes, may attribute to the large variability. More data, therefore, are necessary to obtain a precise estimate of the proportion of time olive ridleys spend at the ocean surface. Finally, environmental (e.g. depth, time of day, temperature) and biological factors (e.g. sex and life stage) that may affect their behavior should also be determined.

\section{Implications for population assessment}

Increases in the number of nesting olive ridley females have been reported for Mexico (Márquez et al. 2002) and Costa Rica (Chaves 1998, 1999, 2002, Chaloupka et al. 2004; Fig. 4). These increases most likely resulted from cessation of harvest at nesting beaches (eggs and females) and of adults and large sub-adults in coastal areas. This observed increase in nesting activity resulted in greater hatchling production and, ultimately, greater numbers of juveniles at sea. A large number of juveniles would have become available starting in the late 1990s, following the extensive beach protection initiated in the early 1990s (DOF 1990). A recent skeletochronological study indicated the median age of sexual maturity of olive ridleys to be approximately $13 \mathrm{yr}$, although it may occur as early as 10 yr (Zug et al. 2006), which coincided with the time between the initiation of nesting beach protection (early 1990s) and the observed large number of olive ridleys in the early 2000s at nesting beaches.

The results of our study demonstrate that the at-sea abundance estimates provide information that is not available from nesting beach censuses. At nesting beaches, only adult females, eggs, and hatchlings are available for observations, whereas at sea, large juveniles and adults of both sexes are available for sampling. Consequently, the data from ship-board line transect sampling provide complementary information to data provided from nesting beach studies. Due to the patchiness of the distribution of olive ridleys in the ETP, estimated abundances had a high degree of uncertainty, i.e. wide CIs. These uncertainties indicated that these estimates are not appropriate for computing the trend of the population; such information needs to be obtained from well-planned nesting beach surveys.

Because of the variability in the number of turtles observed at nesting beaches and at sea, longitudinal studies and surveys are necessary to determine whether or not the population is declining over time. For a large spatial scale study, sampling design should account for patchiness of distribution of turtles. Adaptive sampling (Thompson \& Seber 1996) may be appropriate for this purpose. Our data came from opportunistically collected sightings from surveys of marine mammals, whose distributions were not similar to those of marine turtles. For nesting beach studies, various possibilities exist for obtaining precise trends of a population, such as mark-recapture, saturation tagging, and photo-census.

Finally, to determine possible impacts of anthropogenic mortality on the population, information on fishery by-catch and egg harvest is also required. In 
combination, these data would aid decision making in the long-term management of turtle populations. With location- and time-specific mortality data, management decisions may be made which are specific to age or stage classes, locations, and time of the year. Conversely, effective and successful management of olive ridleys is difficult without knowledge of their spatial and temporal distribution because of the large uncertainty associated with many life history parameters and abundance of the species. However, the general conclusion about the population growth rate needs to be examined when more longitudinal data are available. Given the observed spatial and temporal variability in the density of olive ridleys, it is premature to estimate such quanttities as population growth rate and other population parameters from the line-transect data. Further, on-going studies have indicated that the sizes of non-arribada rookeries may be declining and these rookeries may be isolated demographically from the rest of the eastern Pacific population (A. AbreuGrobois, pers. comm.). Consequently, surveys and genetic sampling are necessary to elucidate the status of the population.

Our results indicate that olive ridleys currently are abundant in coastal and oceanic waters of the ETP, and their numbers are probably still increasing as a result of the protection programs that began in the 1990s. These population estimates are important not only for monitoring the status and trends of this recovering endangered species (IUCN 2006), but will also be essential for assessing the ecological impacts of this physically large and increasingly abundant component of the ETP marine ecosystem (Bjorndal \& Jackson 2003, McClenachan et al. 2006).

In conclusion, through line-transect analysis of sighting data, the best estimate of abundance of olive ridleys in the ETP was 1.39 million $(\mathrm{CV}=19.7 \%$; approximate $95 \% \mathrm{CI}: 1.15$ to 1.62 million). The true abundance was greater because the abundance refers only to large juveniles and the adult portion of the population. However, a large spatial scale longitudinal study combined with the observed temporal and spatial variability in the density is necessary to provide an accurate trend of the true density of olive ridleys in the region and to analyze the effects of human activities on the population. Such information is essential for successful management of olive ridleys in the area. Our study provides the baseline information on the density and abundance of olive ridleys in the ETP to which future studies can be compared. Our results indicate that olive ridleys are abundant in coastal and oceanic waters of the ETP, and may have increased since the 1990s. Considering the relatively high estimated density and abundance of the species, the present 'Endangered' status of olive ridleys under the World Conservation Union (IUCN 2006) should be reviewed.

Acknowledgements. The present study would not have been possible without help from numerous National Marine Fisheries Service (NMFS) observers who have spent hours searching for turtles and marine mammals over the years. We acknowledge the officers and crew of NOAA research vessels 'David Star Jordan', 'McArthur', 'McArthur II' and University National Oceanographic Laboratory System rsearch vessel 'Endeavor' for their logistical support at sea. We thank Lisa Ballance for sharing turtle sighting data. We appreciate the help from Lianne McNaughton and Yonat Swimmer, who kindly shared dive data of olive ridleys in the ETP. Melissa Snover and Eric Archer provided constructive comments on the early version of the manuscript. Ronel Nel, Helene Marsh, and 2 anonymous reviewers provided valuable comments that improved our manuscript.

\section{LITERATURE CITED}

Abreu-Grobois A, Plotkin P (2007) Marine Turtle Specialist Group Red List assessment of the olive ridley turtle (Lepidochelys olivacea). IUCN Red List Programme, Gland

Alava JJ, Pritchard PCH, Wyneken J, Valverde H (2007) First documented record of nesting by the Olive ridley turtle (Lepidochelys olivacea) in Ecuador. Chelonian Conserv Biol (in press)

Beavers SC, Ramsey FL (1998) Detectability analysis in transect surveys. J Wildl Manag 62:948-957

Benson SR, Forney KA, Dutton PH, LaCasella E (2006) Characterization of critical foraging habitat for leatherback turtles off California, USA. In: Frick M, Pnagopoulou A, Rees AF, Williams K (compilers), Book of Abstracts, 26th Annual Symposium on Sea Turtle Biology and Conservation. International Sea Turtle Society, Athens, p182

Bjorndal KA, Jackson JBC (2003) Roles of sea turtles in marine ecosystems: reconstructing the past. In: Lutz PL, Musick JA, Wyneken J (eds) The biology of sea turtles, Vol II. CRC Press, Boca Raton, FL, p 259-273

Broderick AC, Godley BJ, Hays GC (2001) Trophic status drives inter-annual variability in nesting numbers of marine turtles. Proc Royal Society 268:1481-1487

Brower LP, Malcolm SB (1991) Animal migrations: endangered phenomena. Am Zool 31:265-276

Buckland ST, Anderson DR, Burnham KP, Laake JL, Borchers DL, Thomas L (2001) Introduction to distance sampling. Oxford University Press, New York

Buckland ST, Anderson DR, Burnham KP, Laake JL, Borchers DL, Thomas L (2004) Advanced distance sampling. Oxford University Press, New York

Carretta JV, Taylor BL, Chivers SJ (2001) Abundance and depth distribution of harbor porpoise (Phocoena phocoena) in northern California determined from a 1995 ship suvey. Fish Bull 99:29-39

Castège I, Hemery G, Roux N, d'Elbee J, Lalanne Y, D'Amico $F$, Mouches $C$ (2004) Changes in abundance and at-sea distribution of seabirds in the Bay of Biscay prior to, and following, the 'Erika' oil spill. Aquat Living Resour 17: 361-367

Chaloupka ML, Dutton P, Nakano H (2004) Status of sea turtle stocks in the Pacific. Papers presented at the Expert Consultation on Interactions between Sea Turtles and Fisheries within an Ecosystem Context. Fisheries Report, 
No. 738, Suppl, FAO, Rome, p 135-164

Chaves G (1998) Plan de manejo para la utilización racional, manejo y conservación de los huevos de la tortuga marina lora (Lepidochelys olivacea) en el refugio nacional de vida selvestre Ostional, Santa Cruz, Guanacaste, Costa Rica. Informe No. 1998. Escuela de Biologia, Universidad de Costa Rica, San Jose

Chaves G (1999) Anidación de la tortuga lora (Lepidochelys olivacea) en el Refugio Nacional de Vida Silvestre Ostional, Guanacaste. Informe No. 1. Escuela de Biologia, Universidad de Costa Rica, San Jose

Chaves G (2002) Anidación de la tortuga lora (Lepidochelys olivacea) en el Refugio Nacional de Vida Silvestre Ostional, Guanacaste. Informe No. 4. Escuela de Biologia, Universidad de Costa Rica, San Jose

Cheng IJ, Chen TH (1997) The incidental capture of 5 species of sea turtles by coastal setnet fisheries in the eastern waters of Taiwan. Biol Conserv 82:235-239

Cliffton K, Cornejo DO, Felger RS (1995) Sea turtles of the Pacific coast of Mexico. In: Bjorndal KA (ed) Biology and conservation of sea turtles. Revised edn. Smithsonian Institution Press, Washington, DC, p 199-209

Dawson S, Slooten E, DuFresne S, Wade P, Clement D (2004) Small-boat surveys for coastal dolphins: line-transect surveys for Hector's dolphins (Cephalorhynchus hectori). Fish Bull 201:441-451

DOF (1990) Acuerdo por el que se establece veda para las especies y subespecies de tortuga marina en aguas de jurisdicción Federal del Golfo de México y Mar Caribe, así como en las costas del Océano Pacífico, incluyendo el Golfo de California. Diario Oficial de la Federación. Federal Government of Mexico, México, Federal District

Dutton DL, Dutton PH, Chaloupka M, Boulon RH (2005) Increase of a Caribbean leatherback turtle Dermochelys coriacea nesting population linked to long-term nest protection. Biol Conserv 126:186-194

Gerrodette T, Forcada J (2005) Non-recovery of 2 spotted and spinner dolphin populations in the eastern tropical Pacific Ocean. Mar Ecol Prog Ser 291:1-21

Green D, Ortiz-Crespo F (1995) Status of sea turtle populations in the central eastern Pacific. In: Bjorndal KA (ed), Biology and Conservation of Sea Turtles. Revised edn. Smithsonian Institution Press, Washington, DC p 221-234

IUCN - The World Conservation Union (2006) 2006 IUCN Red list of threatened species. Available at: www.iucnredlist. org

Kaplan IC (2005) A risk assessment for Pacific leatherback turtles (Dermochelys coriacea). Can J Fish Aquat Sci 62: 1710-1719

Kinzey D, Gerrodette T (2003) Distance measurements using binoculars from ships at sea: accuracy, precision and effects of refraction. J Cetacean Res Manag 5:159-171

Kinzey D, Gerrodette T, Barlow J, Dizon A, Perryman W, Olson P (2000) Marine mammal data collected during a survey in the eastern tropical Pacific Ocean aboard the NOAA ships McArthur and David Starr Jordan, July 28-December 9, 1999. NOAA Tech Memo NOAA-TMNMFS-SWFSC-293. NOAA, La Jolla, CA

Lewison RL, Crowder LB, Read AJ, Freeman SA (2004) Understanding impacts of fisheries bycatch on marine megafauna. Trends Ecol Evol 19:598-604

Lowry MS, Forney KA (2005) Abundance and distribution of California sea lions (Zalophus californianus) in central and northern California during 1998 and summer 1999. Fish Bull 103:331-343
Márquez-M R, Carrasco-A MA, Jiménez MC (2002) The marine turtles of Mexico: an update. In: Kinan I (ed) Proceedings of the Western Pacific Sea Turtle Cooperative Research and Management Workshop. WESTPAC, Honolulu, HI, p 281-285

McClenachan L, Jackson JBC, Newman MJH (2006) Conservation implications of historic sea turtle nesting beach loss. Front Ecol Environ 4:290-296

McMahon CR, Bradshaw CJA, Hays G (2007) Satellite tracking reveals unusual diving characteristics for a marine reptile, the olive ridley turtle Lepidochelys olivacea. Mar Ecol Prog Ser 329:239-252

Meylan AB (1995) Estimation of population size in sea turtles. In: Bjorndal KA (ed), Biology and conservation of sea turtles. Revised edn. Smithsonian Institution Press, Washington, DC, p 135-138

Pandav B, Choudhury BC, Shanker K (1998) The olive ridley sea turtle (Lepidochelys olivacea) in Orissa: an urgent call for an intensive and integrated conservation programme. Curr Sci 75:1323-1328

Parker D M, Dutton PH, Kopitsky K, Pitman RL (2002) Movement and dive behavior determined by satellite telemetry for male and female olive ridley turtles in the eastern tropical Pacific. In: Seminoff JA (compiler) Proceedings of the 22nd Annual Symposium on Sea Turtle Biology and Conservation. NOAA Tech Memo NMFS-SEFSC-503, NOAA, Miami, FL, p 48-49. Available at: www.nmfs. noaa.gov/pr/species/turtles/symposia.htm

Peñaflores C, Vasconcelos J, Albavera E, Marquez R (2000) Twenty five years nesting of olive ridley sea turtle Lepidochelys olivacea in Escobilla Beach, Oaxaca, Mexico. In: Abreu-Grobois FA, Briseño R, Márquez R, Sarti L (compilers) Proceedings of the 18th International Sea Turtle Symposium. NOAA Tech Memo NMFS-SEFSC-436, NOAA, Miami, FL, p 27-29

Pinedo MC, Polacheck T (2004) Sea turtle by-catch in pelagic longline sets off southern Brazil. Biol Conserv 119: 335-339

Plotkin PT, Byles RA, Rostal DC, Owens DW (1995) Independent versus socially facilitated oceanic migrations of the olive ridley, Lepidochelys olivacea. Mar Biol 122: 137-143

Polovina JJ, Balazs GH, Howell EA, Parker DM, Seki MP, Dutton PH (2004) Forage and migration habitat of loggerhead (Caretta caretta) and olive ridley (Lepidochelys olivacea) sea turtles in the central North Pacific Ocean. Fish Oceanogr 13:36-51

Pritchard PCH (1997) Evolution, phylogeny, and current status. In: Lutz PL, Musick JA (eds) The biology of sea turtles. CRC Press, Boca Raton, FL

Richard JD, Hughes DA (1972) Some observations of sea turtle nesting activity in Costa Rica. Mar Biol 16:297-309

Seber GAF (1982) The estimation of animal abundance and related parameters. 2nd edn. Macmillan, New York

Seminoff JA, Peckham H, Eguchi T, Sarti-Martinez AL, Rangel R, Forney K, Nichols WJ, Dutton PH (2006) Loggerhead turtle density and abundance along the Pacific coast of the Baja California Peninsula, Mexico, determined through aerial surveys: a preliminary assessment. In: Frick M, Pnagopoulou A, Rees AF, Williams K (compilers) Book of Abstracts, 26th Annual Symposium on Sea Turtle Biology and Conservation. International Sea Turtle Society, Athens, p 321

Shanker K, Pandav B, Choudhury BC (2003) An assessment of the olive ridley turtle (Lepidochelys olivacea) nesting population in Orissa, India. BiolConserv 115:149-160

Shanker K, Ramadevi J, Choudhury BC, Singh L, Aggarwal 
RK (2004) Phylogeography of olive ridley turtles (Lepidochelys olivacea) on the east coast of India: implications for conservation theory. Mol Ecol 13:1899-1909

Sugiura N (1978) Further analysis of the data by Akaike's information criterion and the finite corrections. Commun Stat Theory Methods A7:13-26

Swimmer Y, Arauz R, McCracken M, McNaughton L, Ballestero J, Musyl M, Bigelow K, Brill R (2006) Diving behavior and delayed mortality of olive ridley sea turtles Lepidochelys olivacea after their release from longline fishing gear. Mar Ecol Prog Ser 323:253-261

Thomas L, Laake JL, Strindberg S, Marques FFC and 7 others (2003) Distance 4.1, Release 2. Research Unit for Wildlife Population Assessment, University of St. Andrews. Avail-

Editorial responsibility: Helene Marsh, Townsville, Queensland, Australia able at: www.ruwpa.st-and.ac.uk/distance

Thompson SK, Seber GAF (1996) Adaptive sampling. John Wiley \& Sons, New York

Troëng S, Chacón D, Dick B (2004) Possible decline in leatherback turtle Dermochelys coriacea nesting along the coast of Caribbean Central America. Oryx 38:395-403

Valverde RA, Cornelius SE, Mo CL (1998) Decline of the olive ridley sea turtle (Lepidochelys olivacea) nesting assemblage at Nancite beach, Santa Rosa National Park, Costa Rica. Chelonian Conserv Biol 3:58-63

Zug GR, Chaloupka M, Balazs GH (2006) Age and growth in olive ridley seaturtles () from the North-central Pacific: a skeletochronological analysis. Mar Ecol PSZN I: Mar Ecol $27: 263-270$

Submitted: March 22, 2007; Accepted: July 2, 2007

Proofs received from author(s): August 3, 2007 